\title{
MOOD AND PROSPECTIVE MEMORY IN AGING
}

The Detrimental Effects of Mood on Prospective Memory Are Modulated by Age

Francesco Pupillo, Louise Phillips, and Katharina Schnitzspahn

University of Aberdeen, UK

Author Note

Francesco Pupillo, School of Psychology, University of Aberdeen; Louise Phillips, School of Psychology, University of Aberdeen; Katharina Schnitzspahn, School of Psychology, University of Aberdeen.

Correspondence concerning this article should be addressed to Francesco Pupillo, School of Psychology, University of Aberdeen, Aberdeen, AB24 3FX. E-mail: r01fp16@abdn.ac.uk.

Raw data and script of the analysis are available on the Open Science Framework (https://osf.io/378n2/). 


\title{
MOOD AND PROSPECTIVE MEMORY IN AGING
}

\begin{abstract}
Everyday fluctuations in mood can influence our ability to remember to carry out intentions (prospective memory). Theories of mood-cognition interaction make differing predictions about the effects of positive and negative mood states on cognition that may change in aging. To test these predictions, we looked at the effects of age and induced mood on different types of prospective memory tasks. Results showed that on a task which required constant attentional monitoring (event-based prospective memory) young adults' performance was impaired by negative mood, while older adults' performance was not influenced by mood. Further analyses indicated that the deleterious effects of negative mood states in young participants were related to decreased monitoring. In another task which required more intermittent monitoring (time-based prospective memory), older adults' performance actually improved under positive mood, whereas young adults showed no effect of mood. Contrary to predictions, these age differences were not related to improved emotion regulation in old age. We conclude that young adults are more likely than older to show prospective memory failures caused by negative mood. Future research priorities are outlined to better understand the motivational and task characteristics which influence this phenomenon. Keywords: mood, prospective memory, aging, monitoring
\end{abstract}




\section{MOOD AND PROSPECTIVE MEMORY IN AGING}

Does the experience of happy and sad events influence our ability to remember planned intentions? And, if that is the case, is it similarly true for young and older adults? Imagine that you are watching the news in the evening and you have to remember to call a friend afterwards. The news might feature sad events like a terrorist attack or happy events like a victory of your favourite soccer team. Will you still remember to call your friend for her birthday when the news is over? We instinctively might think that affective states are always detrimental for our cognitive performance, as western philosophy has for long time considered emotion and feeling as the opposite of reason (Damasio, 1999). However, recent theories on emotion-cognition interactions and empirical results from developmental research suggest a more complex pattern (Isaacowitz \& Riediger, 2011; Schnitzspahn et al., 2014; Schwarz, 2011; Storbeck \& Clore, 2007). It is still not clear whether negative mood is always detrimental to cognitive performance, compared to a more neutral or positive mood. In addition, developmental studies found evidence that the interplay of emotion and cognition changes in later adulthood. The present project therefore examined the effects of mood on cognition in young and older adults, focusing on prospective memory (PM), the ability to remember and perform delayed intentions (J. Ellis \& Kvavilashvili, 2000).

\section{Mood-Cognition Interactions}

Mood states have been described as prolonged neurophysiological states that are consciously accessible (Russell, 2003). Several models have been proposed in an attempt to explain the effects of mood on cognition.

According to capacity accounts (e.g. Ellis and Ashbrooks' resource allocation model, 1988), strong emotional states lead to the production of irrelevant thoughts, which draw upon the limited resources that the individuals have available to carry out cognitive tasks. As a consequence, positive and negative mood are predicted to have detrimental effects on cognitive performance. Several studies have supported this claim (see H. C. Ellis \& Moore, 


\section{MOOD AND PROSPECTIVE MEMORY IN AGING}

1999, for a review). For instance, Seibert and Ellis (1991) found that participants performed worse on a recall memory task and were more likely to produce task unrelated thoughts under negative and positive mood, compared to participants in a neutral mood condition.

Different theoretical accounts (e.g. the affect-as-information-model, Schwarz \& Clore, 1988; Schwarz, 2011) suggest that affective states might vary in their influence on cognition depending on the specific type of task. For instance, under positive mood people tend to perform better on flexibility, creativity, and word fluency tasks (Isen, 1998; Phillips, Bull, Adams, \& Fraser, 2002), while they perform worse on tasks testing executive functions, such as inhibition, updating, task-switching, and planning (Oaksford, Morris, Grainger, \& Williams, 1996; Phillips et al., 2002). In contrast, under negative mood individuals performed better in false memory tasks by reducing the use of implicit associations (Storbeck \& Clore, 2005). Similarly, performance was also improved under negative mood in eyewitness testimony by reducing the tendency to incorporate misleading information (Forgas, Laham, \& Vargas, 2005). These findings suggest that the effects of mood on cognition may vary as a function of the cognitive process involved.

\section{Effects of Mood on Prospective Memory (PM)}

PM is crucial to maintain independence in later life (Woods, Weinborn, Velnoweth, Rooney, \& Bucks, 2012), by succeeding in everyday PM challenges such as remembering to take medication or pay bills on time. Research on PM and aging is particularly important because PM deficits reduce quality of life in older adults (Woods et al., 2012). Researchers typically distinguish between event-based (EBPM) and time-based (TBPM) tasks, in relation to the nature of the retrieval occasion (Kvavilashvili \& Ellis, 1996; McDaniel \& Einstein, 2007). In EBPM, prospective remembering is triggered by a cue, which prompts individuals to retrieve the intention (e.g. remembering to pick up an item while in a supermarket), 


\section{MOOD AND PROSPECTIVE MEMORY IN AGING}

whereas in TBPM the intention has to be initiated after a certain amount of time has elapsed (e.g. remembering to take the cake out of the oven after 10 minutes).

Only a few studies have investigated the effects of mood on PM performance, with contrasting results. A study by Rummel, Hepp, Klein and Silberleitner (2012) investigated the effects of positive and negative mood on an EBPM task in young adults. In this study, participants were engaged in a lexical-decision task, where they were asked to decide whether or not a string of letters appearing on the screen formed a word. For the PM task, they were required to press a key every time the word they were seeing constituted a verb. Results showed that participants in a negative mood performed better than participants in a positive mood, while there were no differences between either group and the neutral condition. Rummel et al. (2012) interpreted their findings as support for processing-style-accounts (Storbeck \& Clore, 2007). EBPM tasks require subjects to constantly monitor the environment and the ongoing task stimuli for the detection of the target cues (Cona, Arcara, Tarantino, \& Bisiacchi, 2012; Gonneaud et al., 2014). Rummel et al. (2012) suggested that this constant monitoring might benefit from a more local processing style adopted under negative mood. However, monitoring was not reported in the study and therefore the hypothesis could not be tested.

Negative mood has been found to impair TBPM in a study by Kliegel et al. (2005). In this study, young adults had to remember to press a button every minute, while being engaged in a working memory ongoing task using words. Before the task started, participants' mood was induced through either negative or neutral film clips. Results showed performance impairments in those participants who responded to the negative mood induction. Monitoring was measured as the number of clock checks and their mean time deviations from the target times. Results suggested less frequent and less accurate clock 


\section{MOOD AND PROSPECTIVE MEMORY IN AGING}

checks under negative compared to neutral mood. The authors argued that monitoring behaviour therefore mediated mood effects on TBPM but did not run a mediation analysis.

The detrimental effect of mood on TBPM was replicated in a study by Schnitzspahn et al. (2014). Using the same procedure and PM task as Kliegel and colleagues (2005), they found that not only negative but also positive mood impaired TBPM in young adults. Further mediation analyses suggested that the detrimental effects of mood on TBPM performance in young adults were explained by reduced time-monitoring. These results together with the monitoring data reported by Kliegel et al. (2005) do not support the idea that negative mood improves monitoring in PM tasks. Results are rather in line with the resource allocation model (Ellis \& Ashbrook, 1988). Especially the findings by Schnitzspahn et al. (2014) suggesting similarly impairing effects of negative and positive mood on TBPM in young adults seem to be in line with the prediction that mood states generally reduce available cognitive resources and thereby reduce performance in complex cognitive control tasks. However, the contrasting results to date allow no conclusive evidence on the relationship between mood and PM and the theory best explaining it, as monitoring processes differ in EBPM and TBPM tasks. While EBPM tasks require subjects to constantly monitor the environment and the ongoing task stimuli for the detection of the target cues, TBPM requires periodic monitoring of the elapsed time (e.g. Cona et al., 2012). Individuals under negative mood might get too absorbed in the details of the ongoing task and their capacity to trigger time-checking and eventually execute time-based intentions might be impaired, while the same focus on the ongoing task might actually improve monitoring and performance in an EBPM task as suggested by Rummel and colleagues (2012). Further studies directly comparing performance in both PM task types while manipulating mood are needed to determine if mood effects on PM are moderated by the task type and mediated by changes in underlying monitoring behaviour. 


\section{MOOD AND PROSPECTIVE MEMORY IN AGING}

The described study by Schnitzspahn et al. (2014) included not only young, but also older adults. It intriguingly found no effect of mood on TBPM performance in older adults. This issue of age differences in the impact of mood on cognition is now further considered.

\section{Effects of Mood on Cognition in Older Adults}

Aging research suggests that emotional and cognitive abilities follow different developmental trajectories. In fact, despite an overall cognitive decline which occurs in later life, emotional functioning seems to remain stable and, in some cases, even improve with age (Blanchard-Fields, 2005). Older adults tend to prioritise emotionally meaningful contents (Carstensen, Mikels, \& Mather, 2006) and particularly favour attending to, and processing of, positive information over negative. This "positivity effect" in aging (Reed, Chan, \& Mikels, 2014) might be explained by diverted attention towards positive information as a mood-repair strategy in older adults (Isaacowitz, Toner, Goren, \& Wilson, 2008).

It has been suggested that the higher levels of wellbeing and positive affect experienced by older adults may be linked to increased emotion regulation abilities (Urry \& Gross, 2010). However, recent literature queries a general age benefit in the effectiveness of emotion regulation (Isaacowitz, Livingstone, \& Castro, 2017). Especially cognitively demanding emotion regulation strategies such as cognitive reappraisal (i.e. reinterpreting an emotional-eliciting situation to change its emotional impact, Gross \& John, 2003) have been shown to be less effective in older compared to young adults (Tucker, Feuerstein, MendeSiedlecki, \& Ochsner, 2012). Nevertheless, older adults' increased experience and knowledge of effective emotion regulation may still increase the spontaneous use of adaptive strategies (Scheibe, Spieler, \& Kuba, 2016) that are appropriate for the given situation and available cognitive resources. One such strategy that has been shown to be more effective in older compared to young adults (e.g. Wirth \& Kunzmann, 2018) is suppression, a form of emotion regulation that involves inhibiting emotion-expressive behaviour (Gross \& John, 2003). 


\section{MOOD AND PROSPECTIVE MEMORY IN AGING}

Compared to their younger counterparts, older adults typically report increased everyday use of suppression (Eldesouky \& English, 2018). As a result, down-regulation of negative emotions might be a default mode for them (Mather, 2012). In a study by Scheibe and Blanchard-Fields (2009), young and older adults were instructed to down-regulate a negative mood that was induced before performing a working memory task. Older adults performed better than without emotion regulation instructions, while young adults' performance was further impaired suggesting that suppressing negative emotion might be less effortful to older adults.

Considering the conceptual and empirical evidence discussed above, two contradictory outcomes can be predicted. The first possibility is that because the choice and application of effective emotion regulation strategies improve with age (Mather, 2012; Urry \& Gross, 2010), and may be less cognitively demanding for older compared to young adults (Scheibe \& Blanchard-Fields, 2009), older people may show less cognitive impairments under acute mood states, compared to young adults. This fits with the data from the only published study to date looking at age differences in mood effects on PM in which both positive and negative mood had detrimental effects on TBPM in young but not older adults (Schnitzspahn et al., 2014). However, it is important to see if this pattern of results indicating effective emotion regulation in older adults can be replicated in a similar TBPM task, and also extended to EBPM tasks which require different types of cognitive demand. Also, the previous study by Schnitzspahn et al. did not include any assessment of emotion regulation in order to test the role of these processes in the age differences found.

A contrasting prediction can also be made. If reduced capacity for cognitive task focus is the major consequence of mood states, as suggested by the resource allocation model (Ellis \& Ashbrook, 1988), older adults' cognitive performance may be more impaired by mood, given their overall reduced cognitive resources (Salthouse, 2009). Such increased 


\section{MOOD AND PROSPECTIVE MEMORY IN AGING}

effects of mood on cognitive performance in old age could be exaggerated further by the increased focus on emotion regulation in older adults (Isaacowitz, Toner, Goren, \& Wilson, 2008). More precisely, a focus on emotion regulation in older adults who already have diminished cognitive capacity may not leave sufficient resources available to work on the cognitive tasks. This pattern of increased mood effects on cognition in older people has been seen in some tasks. Positive mood impaired older but not young adults' performance on a false recall task (Isaacowitz \& Riediger, 2011). Older adults' performance on a planning task declined under positive or negative mood, much more than for young adults (Phillips, Smith, \& Gilhooly, 2002).

\section{The Current Study}

The present study addressed several questions which have been raised by previous research. Studies on young adults' PM have reported opposite effects of negative mood on performance in time- and event-based tasks (Kliegel et al., 2005; Rummel et al., 2012; Schnitzspahn et al., 2014). It is an open question if the differences between the studies were caused by the PM task type (i.e. event- and time-based) that might moderate mood effects on PM. Besides the cue indicating the right situation to initiate the PM task, previous studies also differed in the chosen ongoing tasks and mood induction materials. While Rummel et al. (2012) in their study on EBPM used a relatively easy lexical decision task, both studies examining mood effects on TBPM (Kliegel et al., 2005; Schnitzspahn et al., 2014) used more demanding working memory tasks as ongoing activities. While all previous studies used short film clips to induce mood, they differed somewhat in their application. Rummel et al. (2012) showed them silently and used a cover story. Specifically, they told participants that they were interested in assessing their abilities to estimate other people's body language and instructed them to empathise with the protagonist. Kliegel et al. (2005) combined the film clips with mood-congruent music that was played while participants worked on the PM task. 


\section{MOOD AND PROSPECTIVE MEMORY IN AGING}

Schnitzspahn et al. (2014) showed a second film clip from the same mood valence half way through the PM task to refresh the mood.

To date, the only study on age differences supported the prediction that older adults would show smaller mood effects on PM (Schnitzspahn et al., 2014), but only used one measure of PM, and did not directly address the role of emotion regulation. To address these issues the current study looked at age differences in the effects of mood changes on both EBPM and TBPM tasks within the same sample and keeping all other factors (e.g. the type of mood manipulation and ongoing task) as similar as possible.

Aim 1: The first aim of the study was to test two contrasting theoretical predictions on the effects of mood on different types of PM tasks. All participants worked on both task types (i.e. event- and time-based) to directly test the suggestion that the task type might moderate mood effects on PM. If positive and negative mood states generally reduce task capacity, as suggested by capacity accounts (Ellis \& Ashbrook, 1988), it can be predicted that increases in either mood will impair both types of PM task (Hypothesis 1a). In contrast, if negative mood states cause a change in processing style to more focused local-level task monitoring (Hypothesis 1b), as suggested by the affect-as-information account (Schwarz \& Clore, 1988; Schwarz, 2011), this leads to the prediction that negative mood will enhance performance on EBPM and possibly impair performance on TBPM tasks (Rummel et al., 2012). Our first aim, therefore, is to contrast the predictions of the capacity and affect-as-information models on the effects of negative mood on the two different types of PM task.

Aim 2: The second aim of the study was to test two contrasting theoretical predictions on age differences in mood effects on PM. In our study, a large sample of young and older adults took part. Considering the role of age, two contrasting outcomes can be predicted. Evidence of improvements in the efficiency of emotion regulation in older age (Scheibe \& Blanchard-Fields, 2009) lead to the prediction that any mood effects on PM will be smaller in 


\section{MOOD AND PROSPECTIVE MEMORY IN AGING}

older adults (Hypothesis 2a). On the other hand, the increased focus of older adults on emotion regulation (Carstensen, Mikels, \& Mather, 2006) might compete with already limited cognitive abilities (Salthouse, 2009), resulting in additional impairments in PM performance by mood states (Hypothesis 2b).

Aim 3: The third aim of the study was to test theoretical predictions on the mechanisms underlying mood effects on PM. The third aim of this study was to investigate possible mechanisms that have been suggested by previous theoretical and empirical work to underlie potential mood effects on PM, and any age differences which arise. First, we looked at whether the effects of mood on PM performance were related to changes in taskmonitoring during negative or positive mood, as predicted by the processing-style-accounts (Schwarz \& Clore, 1988; Schwarz, 2011). Second, we tested whether the effects of mood on PM were related to increased intrusive thoughts that participants experience after positive and negative mood inductions, as predicted by the resource allocation model (Ellis \& Ashbrook, 1988). Finally, we tested the prediction that enhanced emotion regulation ability might relate to age-related benefits in the ability to withstand the effects of mood on PM (Scheibe \& Blanchard-Fields, 2009). In particular, we examined whether increased habitual use of expressive suppression in older adults (Eldesouky \& English, 2018) was associated with reduced mood effects on PM performance.

\section{Method}

\section{Participants and Design}

The sample was composed of 112 young adults $\left(M_{\mathrm{age}}=19.94\right.$ years, age range $=18$ $27)$ and 112 older adults $\left(M_{\mathrm{age}}=70.79\right.$, age range $\left.=59-85\right)$. The gender ratio was held constant across mood conditions and age groups $(p s>.060$, see Table 3 in the supplementary material for more details). The choice of the sample size was based on a power analysis which assumed that 210 participants are needed to achieve a power of $1-\beta=.80$ for 


\section{MOOD AND PROSPECTIVE MEMORY IN AGING}

detecting a triple interaction between age, mood and PM task type of medium effect size $\left(\eta^{2}=\right.$ .06). Young participants were students at the University of Aberdeen who volunteered in exchange for course credits. Older participants were recruited through an internal University volunteer participant panel, as well as the local sports village and senior centres located in Aberdeen and surrounding areas. All older participants were reimbursed $£ 10$ for their time.

The study was conducted in accordance with the Declaration of Helsinki and has been approved by the University of Aberdeen School of Psychology Ethics Committee, which adheres to the British Psychological Society ethical guidelines. All participants gave written informed consent before participation.

All participants were randomly assigned to one of three mood conditions. Within this study, task type (event-based, time-based) was a within-participant variable, while mood condition (negative, neutral, positive) was a between participant variable.

\section{Materials and Procedure}

All participants were tested individually in one session, which lasted about 90 minutes. See Figure 1 for an overview of the procedure. After welcoming participants and obtaining informed consent, their initial mood was measured and they were then asked to perform the Mill-Hill Vocabulary Scale (Raven, Raven, \& John Hugh Court, 1989) and the Digit-Symbol subtask of the Wechsler Adults Intelligence Scale (WAIS-IV, Wechsler, 2008) to measure general cognitive ability. To assess mood, the valence subscale of the SelfAssessment Manikin scale (SAM, Bradley \& Lang, 1994) was used. The SAM is a nonverbal 9-point Likert scale which measures a person's emotional state at a precise time-point. The valence subscale ranges from 1 (happy) to 9 (unhappy). SAM measures were taken ten times throughout the experiment at pre-defined time-points (cfr. Figure 1).

Ongoing task. Following previous studies (Kliegel et al., 2005; Schnitzspahn et al., 2014) the PM task was embedded in an $n$-back verbal working memory task. In total, 216 


\section{MOOD AND PROSPECTIVE MEMORY IN AGING}

words from the Affective Norms for English Words list were selected as stimuli (ANEW, Bradley \& Lang, 1999). In the ongoing task, participants viewed a row of words on a computer screen. Each word was presented for $2 \mathrm{~s}$, with a blank screen of $1 \mathrm{~s}$ between each presentation. Participants were instructed to press the "yes" button every time the word shown was the same as the word which occurred two trials before and press the "no" button if that was not the case. Instructions were followed by a practice trial.

The $n$-back task was presented in five different blocks: the ongoing-task-only and the four PM task blocks. The ongoing-task-only block constituted of 42 trials ( 21 words, each repeated twice), while each PM task block comprised 90 trials (45 words, each repeated twice). Each PM block lasted about 4.5 minutes. The order of the words was randomized, with the restriction that one third of the trials were a "yes" response, and two thirds a "no" response.

PM tasks. The order of the PM tasks, time-based and event-based, was counterbalanced to avoid order effects. In addition, both tasks were split into two blocks, so that the induced mood could be refreshed by adding a film clip between the two blocks (see Schnitzspahn et al., 2014, for a similar procedure).

For the EBPM task, participants were shown the six words which served as PM cues, each presented for $2 \mathrm{~s}$ and repeated twice, and instructed to encode them as well as possible. Each cue was presented twice on experimental trials 15, 29, 40, 53, 70, 91 of the first EBPM block, and on experimental trials 7, 22, 35, 52, 72, 92 of the second EBPM block. Participants were instructed to press the Y key every time one of the six PM cues appeared on the screen. Pressing the $\mathrm{Y}$ while a cue was shown, or during the 1s interval showing a blank screen directly following the cue, was considered a correct PM response.

In the TBPM task, participants were instructed to press the Y key at 1-min intervals from the start of the ongoing task as accurately as possible. They were also told that they 


\section{MOOD AND PROSPECTIVE MEMORY IN AGING}

could monitor the time elapsed by pressing the "space key" on the keyboard, to see a digital clock (00:00) for 3s which appeared on the screen below the ongoing task stimuli. Pressing the target key within a time window of $5 \mathrm{~s}$ around each minute was considered a correct response (see, e.g. Schnitzspahn et al., 2014). To assess clock monitoring behaviour, we considered all clock checks within the 15 s interval immediately before the target (1-min intervals), in line with previous studies which have suggested that this is the critical time window in relation to TBPM performance (e.g. Kliegel, Martin, McDaniel, \& Einstein, 2001).

Mood induction. To induce mood, we used film clips of different valence: negative, neutral, positive. As a reminder: mood condition was a between-participants manipulation in this study. The film clips were taken from movies, TV shows, documentaries, and You Tube. The clips lasted on average three minutes and were selected in accordance with material used in previous studies investigating mood (e.g. Gross \& Levenson, 1995; Hewig et al., 2005; Schaefer, Nils, Sanchez, \& Philippot, 2010; Schnitzspahn et al., 2014). Each film clip was edited to create a coherent story and capitalise on its emotional effect (see Table 1 in the supplementary material for detailed information).

Previous research suggests that young and older adults react differently to emotional stimuli (Keil \& Freund, 2009; Kunzmann \& Gruhn, 2005; Mogilner, Kamvar, \& Aaker, 2011). Therefore, in order to have reliable effects of comparable intensity for both age groups, the clips were piloted in separate studies (see supplementary material for further details). As the pilots' results showed age-related differences in emotional reactions to most of the film clips, we selected mainly different film clips for the two age groups. Examples of film clips used in the young adults' sample are a video of a beach for the neutral condition, a collection of funny clips showing parents pretending to steal Halloween treats from their children for the positive condition, and a hanging scene from the movie "Dancer in the Dark" 


\section{MOOD AND PROSPECTIVE MEMORY IN AGING}

for the negative condition. Examples of film clips used in the older adults are a sketch from the British TV series "Fawlty Towers" for the positive condition, a tutorial on the use of the boiler for the neutral condition, and a clip from the movie "Away From Her" set in a retirement home for the negative condition. The film clips were presented on a PC monitor and participants were invited to wear headphones to listen to the audio features. The order of the film clips was randomised.

After the first film clip, mood was assessed. Participants were then asked to perform the first block of the first PM task. The same procedure was repeated before the second PM task block. After the second PM task block, participants were shown a neutral film clip, and invited to relax. At the end of the neutral film clip, mood was measured and the instruction for the next PM task (event- or time-based, depending on the task order) was given. The same order of task instruction, film, and mood assessments and PM task was repeated for the two blocks of the second PM task.

Mood assessment and operationalization. As described above, mood was measured before and after the mood induction using the SAM scale. To examine mood effects on PM, we considered the change of self-reported valence for each participant following the mood induction, with reference to the baseline. Consequently, we subtracted the mean valence baseline scores from the scores after the induction for each participant. Scores above zero represent a mood change in a negative direction, while scores below zero represent a mood change in a positive direction. These difference scores reflecting the strength of mood changes were used in all performed statistical analyses reported below. This approach allows us a more fine-grained analysis of potential mood effects, as we are not just comparing three groups (i.e. positive, negative, neutral) with each other, but we also consider the intensity of mood changes. This bears several advantages: Mood induction studies usually face the challenge that not all participants react to the chosen material in the anticipated way. In 


\section{MOOD AND PROSPECTIVE MEMORY IN AGING}

particular, participants assigned to the negative mood condition may report a neutral or even a positive mood, while participants assigned to the positive mood condition may report a negative mood. These so-called mood non-responders have been excluded in previous studies investigating mood effects on PM (Kliegel et al., 2005; Rummel et al., 2012; Schnitzspahn et al., 2014). The problem with such exclusions is that the criteria used are subjective and differ between studies, the exclusions reduce power and may artificially amplify natural variations in emotional reactions. The latter may limit the generalisability of results to those participants showing strong mood reactions without making it explicit.

Post-test questionnaires. After finishing the last PM task block, participants were invited to answer a post-test questionnaire, rating the extent to which they experienced emotions and thoughts about the film clips during the memory tasks, on a scale ranging from 1 ("not at all") to 7 ("a great deal"). Participants were then invited to answer the Emotion Regulation Questionnaire (ERQ, Urry \& Gross, 2010). The ERQ contains ten 7-point Likertscale items, ranging from 1 ("strongly disagree") to 7 ("strongly agree") that are designed to assess individual differences in the daily use of two emotion regulation strategies: expressive suppression and cognitive reappraisal. Expressive suppression is a form of emotion regulation that involves inhibiting an emotion-expressive behaviour, while cognitive reappraisal concerns reinterpreting an emotional-eliciting situation to change its emotional impact (Gross \& John, 2003). We obtained separate values on the expressive suppression and cognitive reappraisal scale for each participant.

Finally, before leaving the lab, participants assigned to the neutral and the negative mood condition were presented with a positive film clip and completed a last SAM to ensure that their mood had lifted. Following that, participants were debriefed.

\section{Results}

\section{Effects of Age on Changes in Valence}




\section{MOOD AND PROSPECTIVE MEMORY IN AGING}

To investigate whether participants' mood changed after the mood induction, we considered the changes in valence between the time after the induction and the baseline, collapsed across all types of mood induction. Figure 2 shows valence changes as a function of age group. Older adults' changes in $\operatorname{mood}(M=1.02, S E=0.17)$ were significantly different from young adults' $(M=0.29, S E=0.13), t(203.28)=3.34, p=.001, d=0.46$, as older adults presented stronger changes towards a negative mood.

\section{Prospective Memory}

Before analysing PM performance, 12 participants (3 young adults and 9 older adults) who scored less than or equal to the chance level of $53 \%$ correct in the ongoing task of the PM blocks were identified and excluded from further analyses. In order to analyse PM performance, we used a 3-level mixed logit model, a type of generalised linear- mixed model regression that is designed for binomially distributed outcomes (Agresti, 2003). The choice was motivated by the violation of homogeneity of variance and normality of residuals assumptions in the PM data. Generalised linear-mixed models are generalisations of logistic regression: They describe an outcome through a linear combination of fixed effects and conditional random effects associated with subjects and are recommended in this case (Dixon, 2008; Jaeger, 2008). In the present study, the outcome variable was inherently categorical, as it was composed of limited binary trials: 12 EBPM and eight TBPM trials. In addition, participants' mood changed throughout the experiment as a result of the repeated presentation of mood-inducing materials. The generalised linear mixed-model allowed us to consider whether changes in participants' mood were linked to participants' likelihood to accomplish the PM trials. We treated each trial as binary, either accomplished or not accomplished. Because mood changes and task type (EBPM vs TBPM) were repeated within participants, random slopes were added for both variables within participants. Therefore, accuracy data and mood changes data were nested within task type and within participants by 


\section{MOOD AND PROSPECTIVE MEMORY IN AGING}

adding random intercepts for subjects in the model, and random slopes for task and mood changes. In this way, it was possible to predict the likelihood that a participant at a given affective state has accomplished the PM task or not. Raw data and script of the analysis are available on the Open Science Framework (https://osf.io/378n2/). The equation for the 3level mixed logit model is provided in the supplementary material.

We analysed PM performance as a function of the intensity of changes in mood valence, age group (young vs older adults), and task type (EBPM vs TBPM), which were entered as fixed effects into the model. As random effects, we had intercepts for subjects, as well as random slopes for the effect of intensity of valence changes and task type. P-values were obtained by comparing the deviance of the full model with a model without the effect in question. This difference is known as likelihood ratio and follows a chi-square distribution (Tabachnick \& Fidell, 2007). Figure 3 shows performance as a function of mood changes, for young and older adults, in both EBPM and TBPM tasks.

The analysis showed significant effects of age group, $\chi^{2}(1)=50.31, p<.001$ on PM performance, with young adults performing better than older adults. In addition, the interaction between task type and age group, $\chi^{2}(1)=17.03, p<.001$, and between task type, age group, and intensity of mood changes, $\chi^{2}(1)=6.17, p=.013$, were also significant. The interactions between age group and task type, intensity of mood changes and age group, intensity of mood changes and task type and the main effects of intensity of mood changes and task type were not significant, $p \mathrm{~s}>.066$. The coefficients and the relative odds ratios (OR) are presented in Table 1.

Following up the mood changes $\mathrm{x}$ age $\mathrm{x}$ task type interaction, we analysed the two tasks (EBPM vs TBPM) separately. In addition, in order to understand whether the observed effects of changes in mood were primarily driven by positive or negative valence, we performed a regression spline analysis (see, e.g. Friedman, 1991). Instead of fitting one single 


\section{MOOD AND PROSPECTIVE MEMORY IN AGING}

linear regression to the data, this analysis investigates whether the data can be best explained by fitting two linear regressions with different slopes: one regression with a particular slope until a certain knot point, the second regression with a different slope from that point onward. In the present study, our knot point is zero, representing no change in mood. The two fitted regression slopes will describe changes in valence towards a more positive mood or a more negative mood, compared to the baseline. This analysis therefore allows us to test if effects of mood changes on PM differ as a function of the specific valence (i.e. positive vs negative).

Applying this approach to EBPM and TBPM separately, the splines analyses revealed a significant age by valence interaction in EBPM driven by the negative valence, $\chi^{2}(1)=$ $6.23, p=.012$. In young adults, the stronger the negative mood experienced, the lower was EBPM performance, $b=-0.38, S E=0.14, p=.008, \mathrm{OR}=0.68$, while older adults were not influenced by negative mood changes, $b=0.07, S E=0.11, p=.509, \mathrm{OR}=1.07$. As a result, older adults experiencing negative mood were more likely to accomplish an EBPM task compared to young adults under negative mood, $b=0.45, S E=0.18, p=.021, \mathrm{OR}=1.75$. For TBPM, there was a significant age by positive valence interaction, $\chi^{2}(1)=5.54, p=.019$ : Older adults' performance on the TBPM task improved more during increased positive mood compared to young adults' performance, $b=1.04, S E=0.44, p=.019, \mathrm{OR}=2.82$. The interaction between negative valence and age did not reach significance, $\chi^{2}(1)=1.29, p=$ .256. In addition, the main effects of positive valence, $\chi^{2}(1)=3.81, p=.051$, and negative valence, $\chi^{2}(1)=3.09, p=.079$, approached significance. Participants' performance on TBPM tasks tended to improve during positive mood, $b=0.45 S E=0.23, p=.051, \mathrm{OR}=1.57$, and to decline during negative mood, $b=-0.29, S E=0.16, p=.078, \mathrm{OR}=1.35$.

\section{Ongoing Task: n-back performance}

Investigating the $n$-back task, we analysed the percentage of correct answers (accuracy). Accuracy was submitted to a linear mixed model regression, with task type 


\section{MOOD AND PROSPECTIVE MEMORY IN AGING}

(event- and time-based), age group (old vs young), and changes in valence as fixed effects, while subjects were added to the model as random intercepts. As the accuracy data showed strongly negatively skewed distributions, data were first transformed by applying reverse transformation, then a constant (1) was added, and finally the distribution was reflected again before applying the square root transformation (see Osborne, 2003). The first analysis showed a main effect of age group, $\chi^{2}(1)=4.66, p=.042$, with older adults performing significantly worse than young (untransformed data: $M=91.28, S E=0.46$ for older adults; $M=93.07, S E=0.44$, for young adults). There were no main effects of task type and valence, $p s>.303$. In addition, the interactions between age group and mood, age group and task type, and age group, task type and mood, did not reach significance, $p \mathrm{~s}>.369$.

\section{Exploratory Analyses Investigating the Age and Mood Effects on Prospective Memory}

Links between the observed effects of mood and age on PM performance with monitoring, intrusive thoughts and emotion regulation were considered.

Monitoring. To investigate monitoring in EBPM, we considered RT slowing in the ongoing (n-back) task in the PM task blocks compared to the ongoing task only block. This difference in average RTs during the ongoing task is thought to reflect the deployment of attention to support completing the intention and has been referred to as task interference or PM cost (Hicks, Marsh, \& Cook, 2005). A linear mixed-effects model was run, with PM cost as outcome and age group (young vs older adults), changes in valence, and the two fitted regression splines for negative and positive mood as predictors. Results revealed a greater PM cost for young adults compared to older adults, $b=107.06, S E=30.9, p=.001$. In addition, there was a significant interaction between the negative mood changes and age group, $\chi^{2}(1)=10.56, p=.001$. Young adults experiencing a negative mood showed a decreased PM cost compared to older adults experiencing negative mood, $b=-60.28 S E=$ $18.55, p=.002$. This relationship is shown in Figure 4. Follow-up analyses revealed that 


\section{MOOD AND PROSPECTIVE MEMORY IN AGING}

young adults experiencing a more negative mood showed a significantly smaller PM cost, $b$ $=-44.33 S E=9.74, p<.001$, suggesting that they monitored less. On the contrary, PM cost did not change as a function of positive or negative mood in older adults, $b=-27.7, S E=$ $18.1, p=.129$.

To directly test if this apparently reduced monitoring under negative mood explained the observed mood effects on EBPM in the young adults, we analysed a new model of EBPM performance. The generalised linear mixed model with PM accuracy as dependent variable and age group and mood as predictors outlined above was rerun to include PM cost as an additional predictor. Including PM cost in the model decreased the mood by age effects on accuracy, $b=-0.26, S E=0.14, p=.073$, and also decreased the amount of unexplained information in the model, $\chi^{2}(1)=3.87, p=.049$. Moreover, in young adults, the unbiased estimate of between-subjects indirect effect was $b=0.009,95 \%$ CI $[-0.014,-0.005]$. As the CI does not contain zero, it is likely to be a genuine indirect effect, showing that PM cost partially mediated the effects of mood on EBPM accuracy in young adults.

In order to analyse time monitoring in the TBPM task, we considered all clock checks within the 15 s intervals preceding the PM target times (e.g. Kliegel et al., 2001). A linear regression model with time monitoring as dependent variable and age and changes in mood valence was run. Results showed that there was a significant age effect, $t(190)=7.10, p<$ .001 , showing that young adults $(M=3.70, S E=0.25)$ monitored the time significantly more than older adults $(M=1.11, S E=0.20)$. However, there was no effect of valence on time monitoring, $t(190)=1.29, p=.198$, and no interaction between changes in valence and age group on time monitoring, $t(190)=0.36, p=.971$.

Intrusive thoughts. To explore if mood effects on PM might be mediated by intrusive thoughts, in the post-test questionnaire we asked participants to what extent they thought about the contents of the film clips while performing the PM tasks. An exploration of 


\section{MOOD AND PROSPECTIVE MEMORY IN AGING}

the distribution of intrusive thoughts in each age group showed a marked positively skewed distribution that violated the assumption of normality (Shapiro-Wilk test $p<.001$ for both young and older adults). Therefore, we used bootstrapping to estimate $95 \%$ bootstrapped bias corrected confidence intervals in a linear regression (Efron \& Tibshirani, 1994), to investigate potential effects of age group and mood change on intrusive thoughts. The analysis showed that older adults reported thinking about the film clips during the PM tasks significantly less than their younger counterparts, $b=-.85,95 \%$ BCa CI $[-1.24,-.46], S E=.20, p=.001$, and that intrusive thoughts were increased for participants experiencing a more negative mood, $b$ $=.82,95 \% \mathrm{BCa}$ CI $[.28,1.27], S E=.25, p=.001$. The interaction between age group and mood change approached significance, $b=-.26,95 \%$ BCa CI $[-.54, .058], S E=.15, p=.069$. However, adding intrusive thoughts as predictor in the generalised linear mixed model with age group, changes in valence, and positive and negative splines on EBPM and TBPM did not change the amount of unexplained information in the model $\left(\right.$ EBPM: $\chi^{2}(1)=0.35, p=$ 0.555, TBPM: $\left.\chi^{2}(1)=3.11, p=.078\right)$, and therefore intrusive thoughts did not explain any additional variance in the model.

Emotion regulation. Based on the ERQ, we obtained separate scores on the expressive suppression and the cognitive reappraisal scales for each participant. No age differences were found on the two scales of the ERQ, $p \mathrm{~s}>.879$. In order to test whether scores on the ERQ related to the likelihood to experience mood changes, we ran a linear mixed-model regression with valence changes as dependent variable nested within participants, and age group, expressive suppression scores and cognitive reappraisal scores as predictors. There was a significant effect of age group, $\chi^{2}(1)=9.40, p=.002$, showing more substantial valence changes towards a negative mood for older adults compared to young adults. There was no effect of expressive suppression and cognitive reappraisal on valence change, and no interaction between age group and the emotion regulation scales, $p \mathrm{~s}>.648$. 


\section{MOOD AND PROSPECTIVE MEMORY IN AGING}

To check whether emotion regulation strategy related to PM accuracy, two generalised linear mixed models with PM accuracy as dependent variable and age group, expressive suppression and cognitive reappraisal as predictors were run, for EBPM and TBPM respectively. For EBPM, there was a significant effect of age group, $\chi^{2}(1)=3.94, p=$ .047 , no effect of cognitive reappraisal, $\chi^{2}(1)=1.62, p=.203$, expressive suppression, $\chi^{2}(1)$ $=0.376, p=.540$, and no interaction between age group and cognitive reappraisal, $\chi^{2}(1)=$ $0.004, p=.973$, and age group and expressive suppression, $\chi^{2}(1)=0.01, p=.957$. For TBPM, there was an effect of age group, $\chi^{2}(1)=54.33, p<.001$, no main effects of cognitive reappraisal, $\chi^{2}(1)=0.09, p=.759$, and expressive suppression, $\chi^{2}(1)=0.76, p=.382$, and no interaction between cognitive reappraisal and age group, $\chi^{2}(1)=1.18, p=.277$. The interaction between age group and expressive suppression reached significance, $\chi^{2}(1)=4.66$, $p=.031$, revealing that young adults who tended to use more expressive suppression performed worse compared to older adults who tended to use expressive suppression, $b=$ $0.14, \mathrm{SE}=0.07, p=.031$. However, adding expressive suppression as predictor in the generalised linear mixed model with age group, changes in valence, positive and negative splines on TBPM did not change the amount of unexplained information in the model, $\chi^{2}(1)$ $=0.77, p=.379$.

\section{Discussion}

The main aim of this study was to investigate how mood and age influence PM. Our statistical approach allowed a fine-grained analysis of mood effects by considering actual changes in mood and their intensity on performance. In addition, we directly tested the conceptual proposition that mood effects on PM may differ as a function of the task type (Rummel et al., 2012). Based on theories of emotion-cognition interactions, another aim of 


\section{MOOD AND PROSPECTIVE MEMORY IN AGING}

this study was to investigate mechanisms that may underlie potential mood effects on PM and age differences therein, namely monitoring, intrusive thoughts and emotion regulation.

As expected, results showed an interaction between age, mood changes, and task type. Analysing both task types separately, interactions between age and mood changes on EBPM and TBPM were observed. Specifically, EBPM performance in young adults experiencing negative mood was impaired, while older adults' performance was not significantly affected by negative mood. Conversely, older adults benefitted from positive mood on the TBPM task, while this was not the case for young adults. The impairing effect of negative mood on EBPM in the young adults may be explained by reduced monitoring reflecting a shift in the use of attentional resources under negative mood. However, we still do not have a clear explanation for why such an effect is not seen in older adults. Results indicated that older adults' ability to show resilient cognitive performance under strong mood states cannot be explained by a generally different emotion regulation style compared to young adults.

None of the theories on effects of mood on cognition outlined in the introduction can fully explain the pattern of results observed in this study. According to the mood-asinformation theory (Schwarz \& Clore, 1988; Schwarz, 2011), we should have observed performance improvements in the EBPM and impairments in the TBPM task under negative mood. By contrast, in line with predictions from the resource allocation model (Ellis \& Ashbrook, 1988), we should have found overall impairments for both negative and positive mood. Our data partially support the resource allocation model, as we observed performance impairments under negative mood in the EBPM task for young adults. Data also showed that the detrimental effects of negative mood can be explained by reduced monitoring, supporting the view that negative mood might reduce the resources available for the task at hand. 


\section{MOOD AND PROSPECTIVE MEMORY IN AGING}

However, performance was not impaired under positive mood. Conversely, performance on the TBPM task was improved by positive mood in older adults.

The improvements observed under positive mood in older adults might be attributable to motivational and volitional components accompanying mood states. The theoretical approaches described above do not take these into consideration and instead try to explain mood effects on cognition purely with changes in the underlying cognitive processes. In fact, it has been shown that positive mood is related to increased feelings of energy, approach behaviours (e.g. higher engagement in activities), and a greater sense of control (Lyubomirsky, King, \& Diener, 2005). Thus, positive mood may increase the willingness to work on a cognitive task, while negative mood may make it seem an impossible challenge leading to withdrawal (Gendolla, 2012). The increased task engagement under positive mood may then lead to enhanced performance (Brose, 2014; Martin et al., 1993). It has also been suggested that cognitive impairments observed under negative mood can be attributed to motivational factors, like a lack of initiative (Hertel, 2000). According to this view, asking participants to pay more attention to the task can eliminate the detrimental effects of negative mood on memory. Although it has been noted that encouraging focused attention increases the allocation of resources to the task, in line with the resource allocation model (Ellis \& Moore, 1999), it is evident that a theoretical approach explaining the effects of mood on cognition should integrate both cognitive and motivational aspects.

The increased motivation to perform well on the cognitive task (Altgassen et al., 2010; Cook, 2015) might also be a possible explanation for the lack of negative mood effects on PM in older adults. Their increased motivation, compared to young adults, would allow them to focus more on the task and less on their mood, damping the detrimental effects of mood-related distraction. Research on motivation has shown that increased motivation enhances attention to the stimulus and recalibrates the allocation of processing resources in 


\section{MOOD AND PROSPECTIVE MEMORY IN AGING}

favour of the task at hand (Pessoa, 2009). Future research should include measures of motivation when examining effects of mood on cognitive behaviour to test these ideas and help develop a more complex and holistic theory.

Older adults might have also found the task more difficult and challenging, compared to young adults, as suggested by their reduced PM and OT performance. As a consequence, older adults might have dedicated more effort to perform well at the task, and this increased effort might have prevented them from focusing on their mood. This would be in line with studies finding that the effects of negative mood were attenuated when task demands were high (Van Dillen \& Koole, 2007).

The finding that negative mood impaired EBPM in young but not older adults is in line with previous research on age and mood effects in PM (Schnitzspahn et al., 2014). It is important to point out that the absence of negative mood effects on PM in older adults cannot be explained by weak mood changes, as our analysis showed that the changes in valence were even stronger for older adults compared to young adults. These stronger changes towards a more negative mood observed in the older adults are likely due to their more positive mood at baseline (see Table 2 in the supplementary material).

As explained in the introduction, one popular and plausible explanation why older adults could be better able to cope with a cognitive task and the experience of mood changes at the same time is that older adults are better emotion regulators and therefore manage to control their emotions and focus on the cognitive task. The present study suggests that young and older adults do not differ concerning their chosen emotion regulation strategy (i.e. suppression vs reappraisal) and most importantly, no effect of emotion regulation strategies on PM were found. Thus, the hypothesis that emotion regulation may moderate mood effects on PM could not be confirmed. However, it is important to note that we assessed two types of habitual emotion regulation strategy. Therefore, it is not clear whether participants might or 


\section{MOOD AND PROSPECTIVE MEMORY IN AGING}

might not have used specific emotion regulation strategies during the PM tasks, and to what extent they were efficient in using the chosen strategy. Future studies should therefore explicitly manipulate emotion regulation strategies (e.g. Scheibe \& Blanchard-Fields, 2009) or measure online emotion regulation efforts during cognitive task processing.

Based on the theoretical assumptions of capacity accounts (Ellis \& Ashbrook, 1988), intrusive thoughts have been considered in the present study as another factor potentially mediating mood effects on PM. The current results showed that intrusive thoughts were associated with negative mood, in line with previous research (e.g. Smallwood, Fitzgerald, Miles, \& Phillips, 2009). In addition, young adults reported thinking about the film clips while engaged in the PM task significantly more than older adults. A possible explanation for this age-related reduction in intrusive thoughts is that older people require more cognitive resources and greater levels of concentration to execute cognitive tasks (Erskine et al., 2007), leaving less resources for intrusive thoughts to occur (e.g. McVay, Meier, Touron, \& Kane, 2013). However, our analysis suggests that mood effects on PM were not mediated by intrusive thoughts. It is important to point out that intrusive thoughts were measured retrospectively after finishing the PM task in the present study. Future studies could consider using online measures of intrusive thoughts, such as thought-sampling probes (Mrazek et al., 2012) during the PM task to obtain more detailed and direct measures.

While previous research observed that TBPM in young adults was impaired under negative mood (Kliegel et al., 2005; Schnitzspahn et al., 2014), the present results suggest that TBPM was not significantly affected by negative mood, in either young or older adults. However, there was a trend for reduced TBPM under negative mood in the young adults. One possible explanation why this trend did not reach significance is that the mood changes in the young adults before working on the TBPM task may not have been strong enough. In fact, the 


\section{MOOD AND PROSPECTIVE MEMORY IN AGING}

range of mood changes before performing the TBPM task was smaller than that observed before EBPM.

It is important to point out that our mood manipulation did influence age effects differently for the two task types. In fact, negative mood reduced age effects in the EBPM task, while positive mood reduced age differences on the TBPM task. Therefore, these results seem to suggest that the task type might modulate age by mood interactions. Future research is needed to test whether the observed effect reflects a true interaction or was rather driven by the fact that our mood by age interaction reaches significance in one task but not in another.

Our results suggest that reduced monitoring for the cues was related to the impairment in EBPM under negative mood observed in the young adults: young adults experiencing a more negative mood monitored less for the cues, and this decrease in monitoring in turn predicted impaired PM performance. These results are in line with Schnitzspahn et al.'s (2014) finding that impairments in TBPM performance due to the effects of mood were mediated by time monitoring. Taken together, these findings suggest that mood interferes with PM by limiting the resources available to engage in monitoring behaviour which sustains successful PM execution. This seems to be a common mechanism underpinning impairing effects of negative mood on both EBPM and TBPM tasks.

It is worth noting that the only study finding that negative mood actually improves PM (Rummel et al., 2012) differs from previous studies (Kliegel et al., 2005; Schnitzspahn et al., 2014) and the current one regarding the ongoing task difficulty. While the other studies used a reasonably demanding 2-back working memory task, Rummel et al. (2012) used a simple lexical decision task, likely to place less demand on cognitive control. Thus, it is possible that participants working on the lexical decision task have sufficient resources left to perform an additional PM task well under negative mood. Future studies should manipulate 


\section{MOOD AND PROSPECTIVE MEMORY IN AGING}

ongoing task difficulty experimentally to clarify the role of ongoing task difficulty in modulating the effects of mood on PM.

Further, it is worth pointing out that the beneficial effect of negative mood that Rummel and colleagues (2012) found was mainly driven by reduced PM performance under positive mood compared to negative mood. On the contrary, performance of both groups did not differ from performance of participants in the neutral control condition. These results may imply that only strong differences in affective states might lead to changes in EBPM that are measurable on a behavioural level. In the current study, the difference in self-assessed valence scores between the baseline and the after-induction measures were stronger for changes towards a negative mood than for the positive mood changes (cf. Figure 2). Thus, the present results cannot rule out the possibility that strong positive mood may also impair PM similarly to strong negative mood, but rather suggests that subtle changes towards a more positive mood seem to have no effect on PM or can even be beneficial for older adults.

These findings are in line with research showing that effect sizes of mood inductions are typically greater for negative mood compared to positive (e.g. Zhang, Yu, \& Barrett, 2014). This may be due to the fact that participants typically report slightly more positive mood than the median point of the rating scale at baseline, making it more difficult to induce further changes towards a more positive mood (Jallais \& Jilet, 2010). In addition, individuals react differently to the materials used for the mood induction. To make the mood induction even more effective, future studies may consider using personalised methods of inducing mood. For example, prompting mood-relevant autobiographical memories has been found to be effective to induce negative mood (see Mayberg et al., 1997; Nixon, Liddle, Nixon, \& Liotti, 2013), while training participants to vividly imagine themselves reliving positive events from their past has been shown to be effective in inducing positive mood (e.g. Vanlessen, De Raedt, Mueller, Rossi, \& Pourtois, 2015). 


\section{MOOD AND PROSPECTIVE MEMORY IN AGING}

It is important to note that the present study manipulated mood after the intention encoding and before its retrieval. However, PM is considered as a process that entails different phases: intention formation, intention retention, intention initiation, and intention execution (Kliegel, Martin, McDaniel, \& Einstein, 2002). One previous study manipulated participants' mood at intention formation (Knight, Brewer, Ball, DeWitt, \& Marsh, 2015). Results from this study showed that negative mood at encoding was detrimental for subsequent retrieval. However, when the mood at retrieval matched the mood at encoding the detrimental effects of negative mood disappeared. Therefore, it is possible that negative mood during the intention initiation and execution stages of PM is not detrimental per se, but it can be detrimental if it differs from the mood at intention encoding as in the current study.

The present study distinguished positive, neutral and negative mood states without considering potential differences in the motivational intensity of the induced mood states within and between valence conditions. Research suggests that states of amusement, joy, or sadness are generally characterised by low approach motivation (Gable \& Harmon-Jones, 2008). In contrast, desire, enthusiasm, and disgust are considered as high approach motivational states (Harmon-Jones, Harmon-Jones, \& Price, 2013). It has been suggested that these different motivational states can affect the scope of attention (Harmon-Jones, Gable, \& Price, 2012). Specifically, high approach motivational states have been shown to narrow the scope of attention, and thus favour processing of information that is in the centre of the attention, while low approach motivational states are thought to broaden the scope of attention. Consequently, high approach motivational states, independent of their valence, should facilitate detection of PM cues that are processed as part of the ongoing task. Future studies manipulating high vs low approach motivational states are needed to test this hypothesis. 


\section{MOOD AND PROSPECTIVE MEMORY IN AGING}

In conclusion, the present study showed that negative mood impaired performance on an EBPM task in young but not in older adults, and that this impairment might be explained by a reduction in monitoring for the PM cues. Moreover, positive mood improved performance in older adults on a TBPM task (but not for young). To answer the questions raised at the beginning of this article, watching news featuring sad events will not impair the ability to remember to call your friend at a precise time. However, if you are a young adult and rely on your ability to spot a note written on a piece of paper as a reminder, you have reasons to be concerned. 


\section{MOOD AND PROSPECTIVE MEMORY IN AGING}

\section{References}

Agresti, A. (2003). Categorical data analysis. John Wiley \& Sons.

Altgassen, M., Kliegel, M., Brandimonte, M., \& Filippello, P. (2010). Are older adults more social than younger adults? Social importance increases older adults' prospective memory performance. Aging, Neuropsychology, and Cognition, 17(3), 312-328.

Blanchard-Fields, F. (2005). Introduction to the special section on emotion-cognition interactions and the aging mind. Psychology and Aging, 20(4), 539-541. doi:10.1037/0882-7974.20.4.539

Bradley, M. M., \& Lang, P. J. (1994). Measuring emotion: The self-assessment manikin and the semantic differential. Journal of Behavior Therapy and Experimental Psychiatry, 25(1), 49-59. doi:10.1016/0005-7916(94)90063-9

Bradley, M. M., \& Lang, P. J. (1999). Affective norms for english words (ANEW): Instruction manual and affective ratings. (Vol.30, No. 1, pp.25-36). Technical report C-1, the center for research in psychophysiology, University of Florida.

Brose, A., Lövdén, M., \& Schmiedek, F. (2014). Daily fluctuations in positive affect positively co-vary with working memory performance. Emotion, 14(1), 1.

Burke, A., Heuer, F., \& Reisberg, D. (1992). Remembering emotional events. Memory \& Cognition, 20(3), 277-290.

Carstensen, L. L., Mikels, J. A., \& Mather, M. (2006). Aging and the intersection of cognition, motivation, and emotion. In Birren, J.E., Warner,K. (Ed.), Handbook of the psychology of aging (6th ed., pp. 343-362). San Diego, CA: Academic Press. doi:10.1016/B978-012101264-9/50018-5

Cona, G., Arcara, G., Tarantino, V., \& Bisiacchi, P. S. (2012). Electrophysiological correlates of strategic monitoring in event-based and time-based prospective memory. Plos One, 7(2), e31659. doi:10.1371/journal.pone.0031659 


\section{MOOD AND PROSPECTIVE MEMORY IN AGING}

Cook, G. I., Rummel, J., \& Dummel, S. (2015). Toward an understanding of motivational influences on prospective memory using value-added intentions. Frontiers in Human Neuroscience, 9, 278.

Damasio, A. R. (1999). The feeling of what happens: Body and emotion in the making of consciousness. New York: Harcourt Brace.

Dixon, P. (2008). Models of accuracy in repeated-measures designs. Journal of Memory and Language, 59(4), 447-456.

Efron, B., \& Tibshirani, R. J. (1994). An introduction to the bootstrap. CRC press.

Eldesouky, L., \& English, T. (2018). Another year older, another year wiser? Emotion regulation strategy selection and flexibility across adulthood. Psychology and aging, 33(4), 572.

Ellis, H. C., \& Ashbrook, P. W. (1988). Resource allocation model of the effects of depression mood states on memory. In K. Fiedler, \& J. Forgas (Eds.), Affect, cognition, and social behaviour: New evidence and integrative attempts. (pp. 25-43). Toronto, Canada: Hogrefe.

Ellis, H. C., \& Moore, B. A. (1999). Mood and memory. In T. Dalgleish, \& M. Power (Eds.), Handbook of cognition and emotion (pp. 193-210). Chichester: Wiley.

Ellis, J., \& Kvavilashvili, L. (2000). Prospective memory in 2000: Past, present, and future directions. Applied Cognitive Psychology, 14(7), S1-S9.

Erskine, J. A., Kvavilashvili, L., Conway, M. A., \& Myers, L. (2007). The effects of age on psychopathology, well-being and repressive coping. Aging and Mental Health, 11(4), 394-404.

Forgas, J. P., Laham, S. M., \& Vargas, P. T. (2005). Mood effects on eyewitness memory: Affective influences on susceptibility to misinformation. Journal of Experimental Social Psychology, 41(6), 574-588. doi:http://dx.doi.org/10.1016/j.jesp.2004.11.005 


\section{MOOD AND PROSPECTIVE MEMORY IN AGING}

Friedman, J. H. (1991). Multivariate adaptive regression splines. The Annals of Statistics, 167.

Gable, P. A., \& Harmon-Jones, E. (2008). Approach-motivated positive affect reduces breadth of attention. Psychological Science, 19(5), 476-482.

Gendolla, G. H. (2012). Implicit affect primes effort: A theory and research on cardiovascular response. International Journal of Psychophysiology, 86(2), 123-135.

Gonneaud, J., Rauchs, G., Groussard, M., Landeau, B., Mézenge, F., de La Sayette, V., . . . Desgranges, B. (2014). How do we process event-based and time-based intentions in the brain? An fMRI study of prospective memory in healthy individuals. Human Brain Mapping, 35(7), 3066-3082. doi:10.1002/hbm.22385

Gross, J. J., Carstensen, L. L., Pasupathi, M., Tsai, J., Götestam Skorpen, C., \& Hsu, A. Y. (1997). Emotion and aging: Experience, expression, and control. Psychology and Aging, 12(4), 590 .

Gross, J. J., \& John, O. P. (2003). Individual differences in two emotion regulation processes: implications for affect, relationships, and well-being. Journal of personality and social psychology, 85(2), 348.

Gross, J. J., \& Levenson, R. W. (1995). Emotion elicitation using films. Cognition and Emotion, 9(1), 87-108. doi:10.1080/02699939508408966

Harmon-Jones, E., Gable, P., \& Price, T. F. (2012). The influence of affective states varying in motivational intensity on cognitive scope. Frontiers in integrative neuroscience, 6, 73.

Harmon-Jones, E., Harmon-Jones, C., \& Price, T. F. (2013). What is approach motivation?. Emotion Review, 5(3), 291-295.

Hertel, P. T. (2000). The cognitive-initiative account of depression-related impairments in memory. In Psychology of learning and motivation (Vol. 39, pp. 47-71). Academic Press. 


\section{MOOD AND PROSPECTIVE MEMORY IN AGING}

Hewig, J., Hagemann, D., Seifert, J., Gollwitzer, M., Naumann, E., \& Bartussek, D. (2005). A revised film set for the induction of basic emotions. Cognition and Emotion, 19(7), 1095-1109. doi:10.1080/02699930541000084

Hicks, J. L., Marsh, R. L., \& Cook, G. I. (2005). Task interference in time-based, eventbased, and dual intention prospective memory conditions. Journal of Memory and Language, 53(3), 430-444. doi:http://dx.doi.org/10.1016/j.jml.2005.04.001

Isaacowitz, D. M., Livingstone, K. M., \& Castro, V. L. (2017). Aging and emotions: experience, regulation, and perception. Current Opinion in Psychology, 17, 79-83.

Isaacowitz, D. M., \& Riediger, M. (2011). When age matters: Developmental perspectives on “cognition and emotion”. Cognition \& Emotion, 25(6), 957-967.

Isaacowitz, D. M., Toner, K., Goren, D., \& Wilson, H. R. (2008). Looking while unhappy: Mood-congruent gaze in young adults, positive gaze in older adults. Psychological Science, 19(9), 848-853.

Isen, A. M. (1998). On the relationship between affect and creative problem solving. In S. W. Russ (Ed.), Affect, creative experience, and psychological adjustment (pp. 3-17). Philadelphia, PA: Brunner/Mazel.

Jaeger, T. F. (2008). Categorical data analysis: Away from ANOVAs (transformation or not) and towards logit mixed models. Journal of Memory and Language, 59(4), 434-446.

Jallais, C., \& Gilet, A. L. (2010). Inducing changes in arousal and valence: Comparison of two mood induction procedures. Behavior research methods, 42(1), 318-325.

Keil, A., \& Freund, A. M. (2009). Changes in the sensitivity to appetitive and aversive arousal across adulthood. Psychology and aging, 24(3), 668.

Kliegel, M., Jäger, T., Phillips, L., Federspiel, E., Imfeld, A., Keller, M., \& Zimprich, D. (2005). Effects of sad mood on time-based prospective memory. Cognition \& Emotion, 19(8), 1199-1213. doi:10.1080/02699930500233820 


\section{MOOD AND PROSPECTIVE MEMORY IN AGING}

Kliegel, M., Martin, M., McDaniel, M. A., \& Einstein, G. O. (2001). Varying the importance of a prospective memory task: Differential effects across time - and event-based prospective memory. Memory, 9(1), 1-11. doi:10.1080/09658210042000003

Kliegel, M., Martin, M., McDaniel, M. A., \& Einstein, G. O. (2002). Complex prospective memory and executive control of working memory: A process model. Psychological Test and Assessment Modeling, 44(2), 303.

Knight, J. B., Brewer, G., Ball, B. H., DeWitt, M. R., \& Marsh, R. L. (2015). The influence of mood on the process and content of encoding future intentions. Quarterly Journal of Experimental Psychology, 68(6), 1082-1100. doi:10.1080/17470218.2014.975729

Kunzmann, U., \& Grühn, D. (2005). Age differences in emotional reactivity: the sample case of sadness. Psychology and Aging, 20(1), 47.

Kvavilashvili, L., \& Ellis, J. (1996). Varieties of intention: Some distinctions and classifications. In M. Brandimonte, G. O. Einstein \& M. A. McDaniel (Eds.), Prospective memory: Theory and applications. (Erlbaum ed., pp. 23-51). New York: Mahwah.

Lyubomirsky, S., King, L., \& Diener, E. (2005). The benefits of frequent positive affect: Does happiness lead to success?. Psychological Bulletin, 131(6), 803-855.

Martin, L. L., Ward, D. W., Achee, J. W., \& Wyer, R. S. (1993). Mood as input: People have to interpret the motivational implications of their moods. Journal of Personality and Social Psychology, 64(3), 317.

Mather, M. (2012). The emotion paradox in the aging brain. Annals of the New York Academy of Sciences, 1251(1), 33.

Mayberg, H. S., McGinnis, S., Liotti, M., Brannan, S. K., Mahurin, R. K., Jerabek, P. A., . . . Fox, P. T. (1997). Reciprocal limbic-cortical function and mood: Converging PET findings in depression and normal sadness. NeuroImage, 5(4 PART II) 


\section{MOOD AND PROSPECTIVE MEMORY IN AGING}

McDaniel, M. A., \& Einstein, G.,O. (Eds.). (2007). Prospective memory: An overview and synthesis of an emerging field. Los Angeles, Calif. ; London: Sage.

McVay, J. C., Meier, M. E., Touron, D. R., \& Kane, M. J. (2013). Aging ebbs the flow of thought: Adult age differences in mind wandering, executive control, and selfevaluation. Acta psychologica, 142(1), 136-147.

Mogilner, C., Kamvar, S. D., \& Aaker, J. (2011). The shifting meaning of happiness. Social Psychological and Personality Science, 2(4), 395-402.

Mrazek, M. D., Smallwood, J., Franklin, M. S., Chin, J. M., Baird, B., \& Schooler, J. W. (2012). The role of mind-wandering in measurements of general aptitude. Journal of Experimental Psychology: General, 141(4), 788.

Nixon, E., Liddle, P. F., Nixon, N. L., \& Liotti, M. (2013). On the interaction between sad mood and cognitive control: The effect of induced sadness on electrophysiological modulations underlying Stroop conflict processing. International Journal of Psychophysiology, 87(3), 313-326. doi:http://dx.doi.org/10.1016/j.ijpsycho.2012.11.014

Oaksford, M., Morris, F., Grainger, B., \& Williams, J. M. G. (1996). Mood, reasoning, and central executive processes. Journal of Experimental Psychology: Learning, Memory, \& Cognition, 22(2), 476-492.

Osborne, J. (2005). Notes on the use of data transformations. Practical Assessment, Research and Evaluation, 9(1), 42-50 .

Pessoa, L. (2009). How do emotion and motivation direct executive control?. Trends in cognitive sciences, 13(4), 160-166.

Phillips, L. H., Bull, R., Adams, E., \& Fraser, L. (2002). Positive mood and executive function: Evidence from Stroop and fluency tasks. Emotion, 2(1), 12-22. doi:10.1037/1528-3542.2.1.12 


\section{MOOD AND PROSPECTIVE MEMORY IN AGING}

Phillips, L. H., Smith, L., \& Gilhooly, K. J. (2002). The effects of adult aging and induced positive and negative mood on planning. Emotion, 2(3), 263-272. doi:10.1037//15283542.2 .3 .263

Pupillo, F., Phillips, L., \& Schnitzspahn, K. (2019, November 22). Mood and Prospective Memory in Aging. https://doi.org/10.17605/OSF.IO/378N2

Raven, J. C., Raven, J. E., \& John Hugh Court. (1989). Mill hill vocabulary scale Psychological Corporation.

Reed, A. E., Chan, L., \& Mikels, J. A. (2014). Meta-analysis of the age-related positivity effect: Age differences in preferences for positive over negative information. Psychology and Aging, 29(1), 1-15. doi:10.1037/a0035194

Rummel, J., Hepp, J., Klein, S. A., \& Silberleitner, N. (2012). Affective state and eventbased prospective memory. Cognition \& Emotion, 26(2), 351-361. doi:10.1080/02699931.2011.574873

Russell, J. A. (2003). Core affect and the psychological construction of emotion. Psychological review, 110(1), 145.

Salthouse, T. A. (2009). When does age-related cognitive decline begin? Neurobiology of aging, 30(4), 507-514.

Schaefer, A., Nils, F., Sanchez, X., \& Philippot, P. (2010). Assessing the effectiveness of a large database of emotion-eliciting films: A new tool for emotion researchers. Cognition and Emotion, 24(7), 1153-1172. doi:10.1080/02699930903274322

Scheibe, S., \& Blanchard-Fields, F. (2009). Effects of regulating emotions on cognitive performance: What is costly for young adults is not so costly for older adults. Psychology and Aging, 24(1), 217.

Scheibe, S., Spieler, I., \& Kuba, K. (2016). An older-age advantage? Emotion regulation and emotional experience after a day of work. Work, Aging and Retirement, 2(3), 307-320. 


\section{MOOD AND PROSPECTIVE MEMORY IN AGING}

Schnitzspahn, K. M., Thorley, C., Phillips, L., Voigt, B., Threadgold, E., Hammond, E. R., . . . Kliegel, M. (2014). Mood impairs time-based prospective memory in young but not older adults: The mediating role of attentional control. Psychology and Aging, 29(2), 264-270. doi:10.1037/a0036389

Schwarz, N., \& Clore, G., L. (1988). How do I feel about it? The informative function of affective states. In K. Fiedler, \& J. P. Forgas (Eds.), Affect, cognition, and social behavior (pp. 44-62). Gottingen: Hogrefe.

Schwarz, N. (2011). Feelings-as-information theory. In P. Van Lange, A. W. Kruglanski \& E. T. Higgins (Eds.), Handbook of theories of social psychology. Thousand Oaks, CA: Sage.

Seibert, P. S., \& Ellis, H. C. (1991). Irrelevant thoughts, emotional mood states, and cognitive task performance. Memory \& Cognition, 19(5), 507-513. doi:10.3758/BF03199574

Smallwood, J., Fitzgerald, A., Miles, L. K., \& Phillips, L. H. (2009). Shifting moods, wandering minds: negative moods lead the mind to wander. Emotion, 9(2), 271.

Storbeck, J., \& Clore, G. L. (2005). With sadness comes accuracy; with happiness, false memory: Mood and the false memory effect. Psychological Science, 16(10), 785-791.

Storbeck, J., \& Clore, G. L. (2007). On the interdependence of cognition and emotion. Cognition and Emotion, 21(6), 1212-1237. doi:10.1080/02699930701438020

Tabachnick, B. G., \& Fidell, L. S. (2007). Using multivariate statistics. Allyn \& Bacon/Pearson Education.

Tucker, A. M., Feuerstein, R., Mende-Siedlecki, P., Ochsner, K. N., \& Stern, Y. (2012). Double dissociation: circadian off-peak times increase emotional reactivity; aging impairs emotion regulation via reappraisal. Emotion, 12(5), 869-874. 


\section{MOOD AND PROSPECTIVE MEMORY IN AGING}

Urry, H. L., \& Gross, J. J. (2010). Emotion regulation in older age. Current Directions in Psychological Science, 19(6), 352-357. doi:10.1177/0963721410388395

Van Dillen, L. F., \& Koole, S. L. (2007). Clearing the mind: a working memory model of distraction from negative mood. Emotion, 7(4), 715.

Vanlessen, N., De Raedt, R., Mueller, S. C., Rossi, V., \& Pourtois, G. (2015). Happy and less inhibited? Effects of positive mood on inhibitory control during an antisaccade task revealed using topographic evoked potential mapping. Biological Psychology, 110, 190200. doi:http://dx.doi.org/10.1016/j.biopsycho.2015.07.004

Wechsler, D. (2008). Wechsler adult intelligence scale-Fourth Edition (WAIS-IV). San Antonio, TX: NCS Pearson, 22, 498.

Wirth, M., \& Kunzmann, U. (2018). Age differences in regulating negative emotions via attentional deployment. Psychology and aging, 33(3), 384.

Woods, S. P., Weinborn, M., Velnoweth, A., Rooney, A., \& Bucks, R. S. (2012). Memory for intentions is uniquely associated with instrumental activities of daily living in healthy older adults. Journal of the International Neuropsychological Society, 18(1), 134-138. doi:10.1017/S1355617711001263

Zhang, X., Yu, H. W., \& Barrett, L. F. (2014). How does this make you feel? A comparison of four affect induction procedures. Frontiers in psychology, 5, 689. 
MOOD AND PROSPECTIVE MEMORY IN AGING

Table 1.

Estimates of Generalised Linear Mixed Model for PM Accuracy as a Function of Mood, Age Group, and Task type.

\begin{tabular}{|c|c|c|c|c|c|c|c|}
\hline Predictor & \multicolumn{4}{|c|}{ Wald's } & \multicolumn{3}{|c|}{$e^{\beta}$} \\
\hline Constant & $0.77(0.21)$ & 11.36 & 1 & $<.001$ & 1.38 & 2.17 & 3.41 \\
\hline Age Group ${ }^{a}$ & $-2.59(0.37)$ & 50.31 & 1 & $<.001$ & 0.04 & 0.07 & 0.15 \\
\hline Valence changes & $0.03(0.12)$ & 0.06 & 1 & .810 & 0.82 & 1.03 & 1.29 \\
\hline Task Type by Age Group & $1.89(0.46)$ & 17.03 & 1 & $<.001$ & 2.70 & 6.65 & 16.34 \\
\hline Valence changes by Task Type & $-0.26(0.15)$ & 3.15 & 1 & .076 & 0.57 & 0.77 & 1.03 \\
\hline
\end{tabular}

${ }^{a}$ Reference level for age group was young adults.

${ }^{b}$ Reference level for task type was time-based. 
MOOD AND PROSPECTIVE MEMORY IN AGING
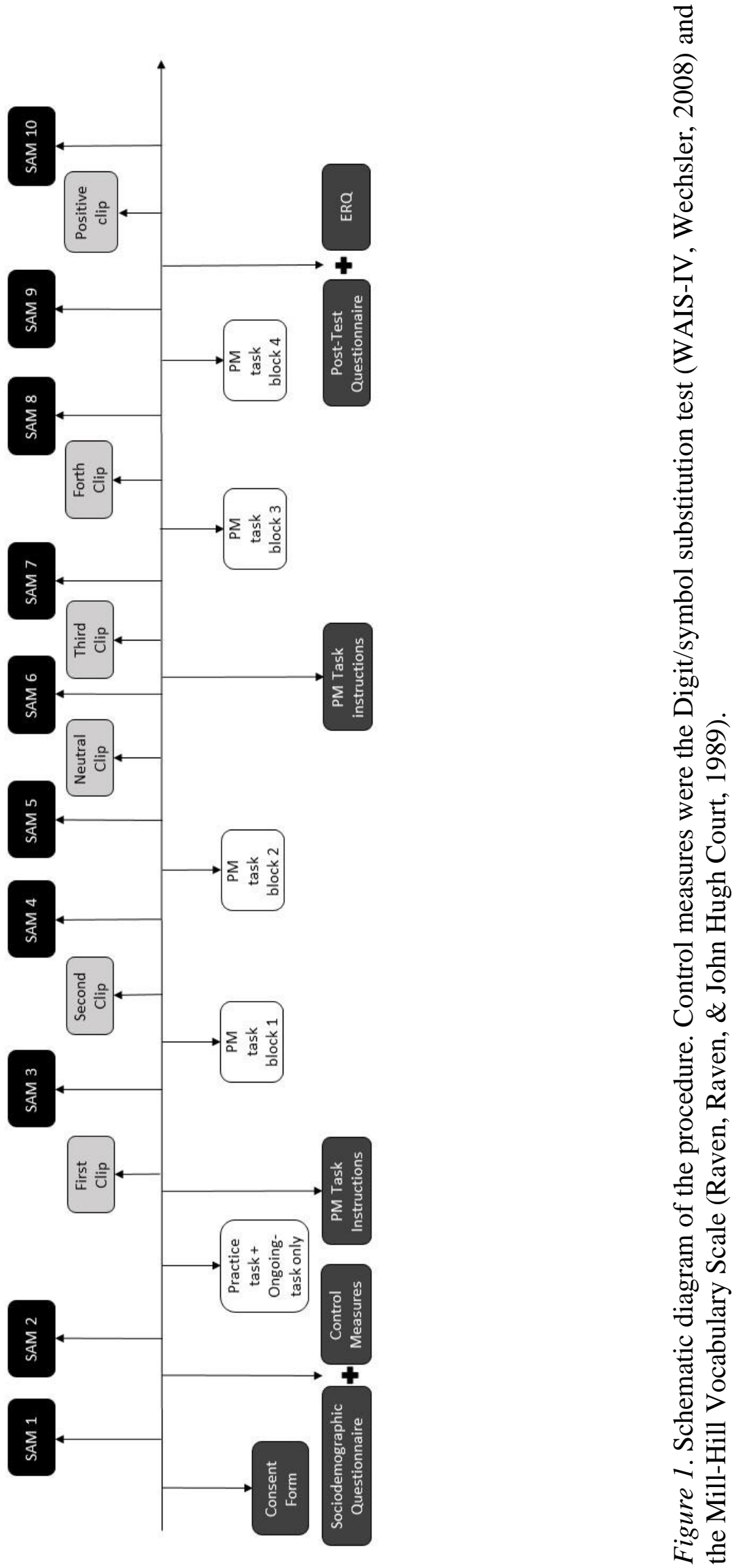


\section{MOOD AND PROSPECTIVE MEMORY IN AGING}

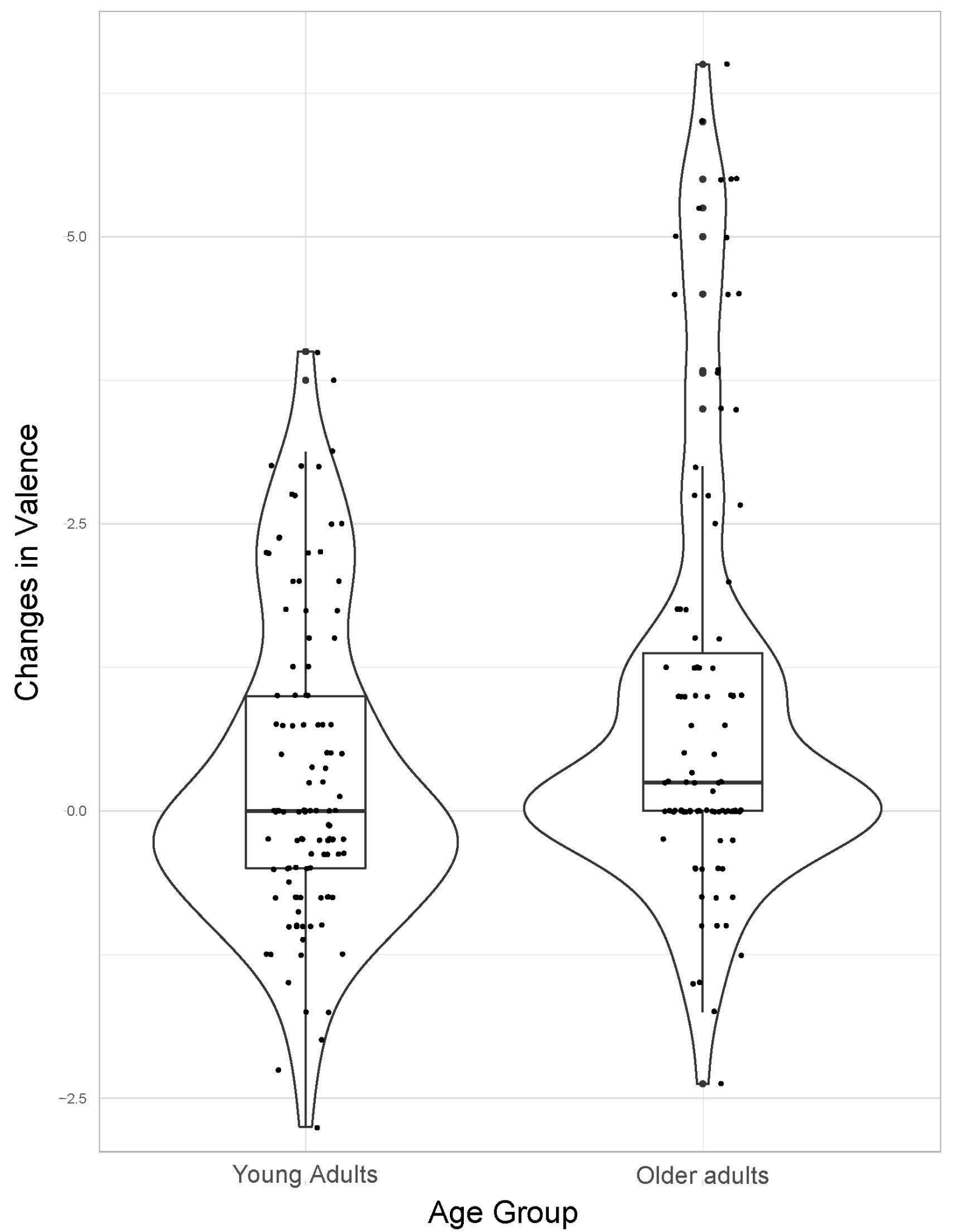

Figure 2 - Violin plots representing the frequency of the changes in valence after the mood induction as a function of age group. Values greater than zero refer to a more negative mood, while values smaller than zero refer to a more positive mood. 
MOOD AND PROSPECTIVE MEMORY IN AGING

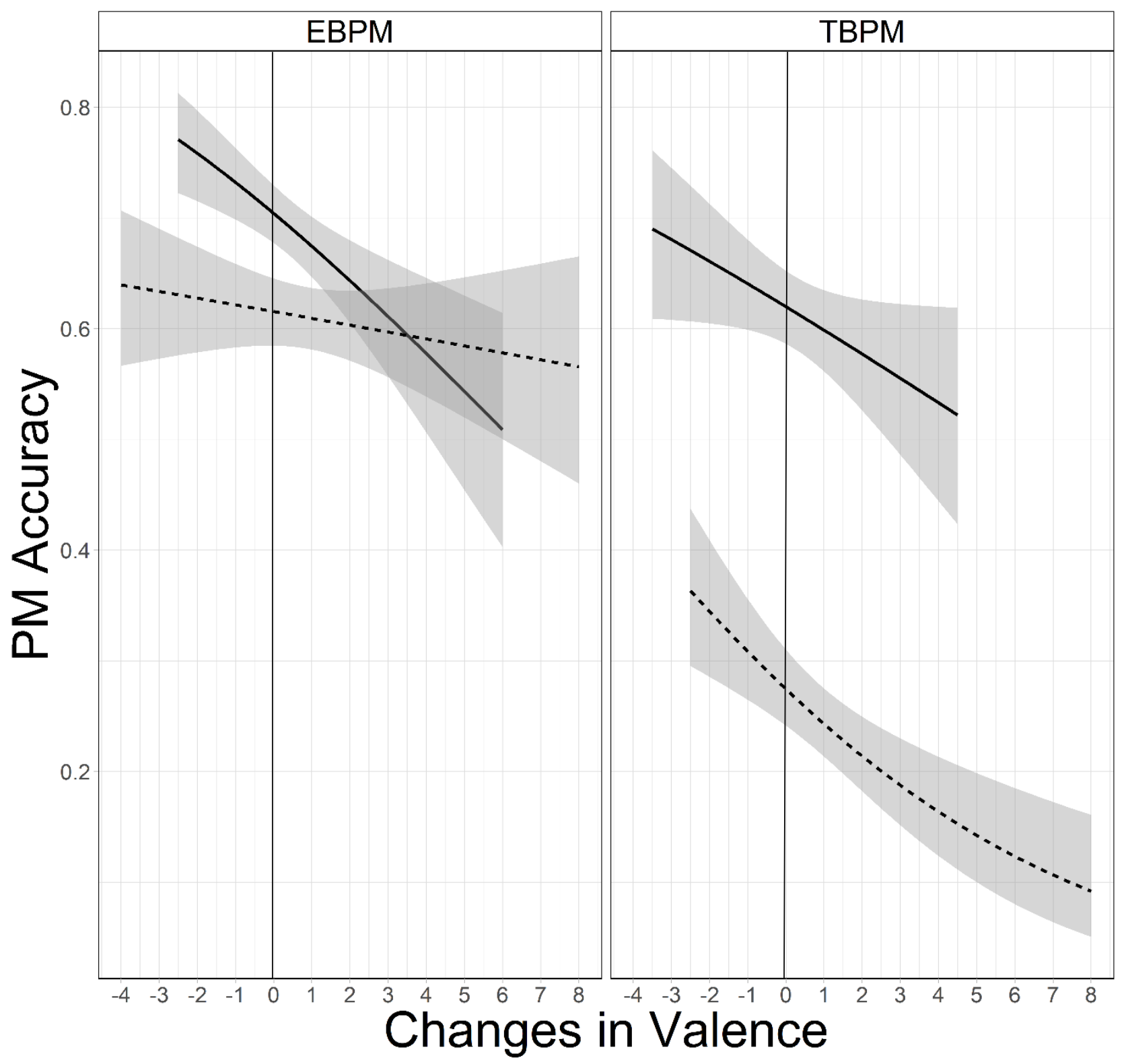

Age Group -Young Adults -- Older Adults

Figure 3. The effect of mood, age group, and task type on performance. Changes in valence refer to the changes in mood valence after the induction, compared to the baseline. Values greater than zero refer to a more negative mood, while values smaller than zero refer to a more positive mood. The shaded areas represent $95 \%$ confidence intervals. 
MOOD AND PROSPECTIVE MEMORY IN AGING

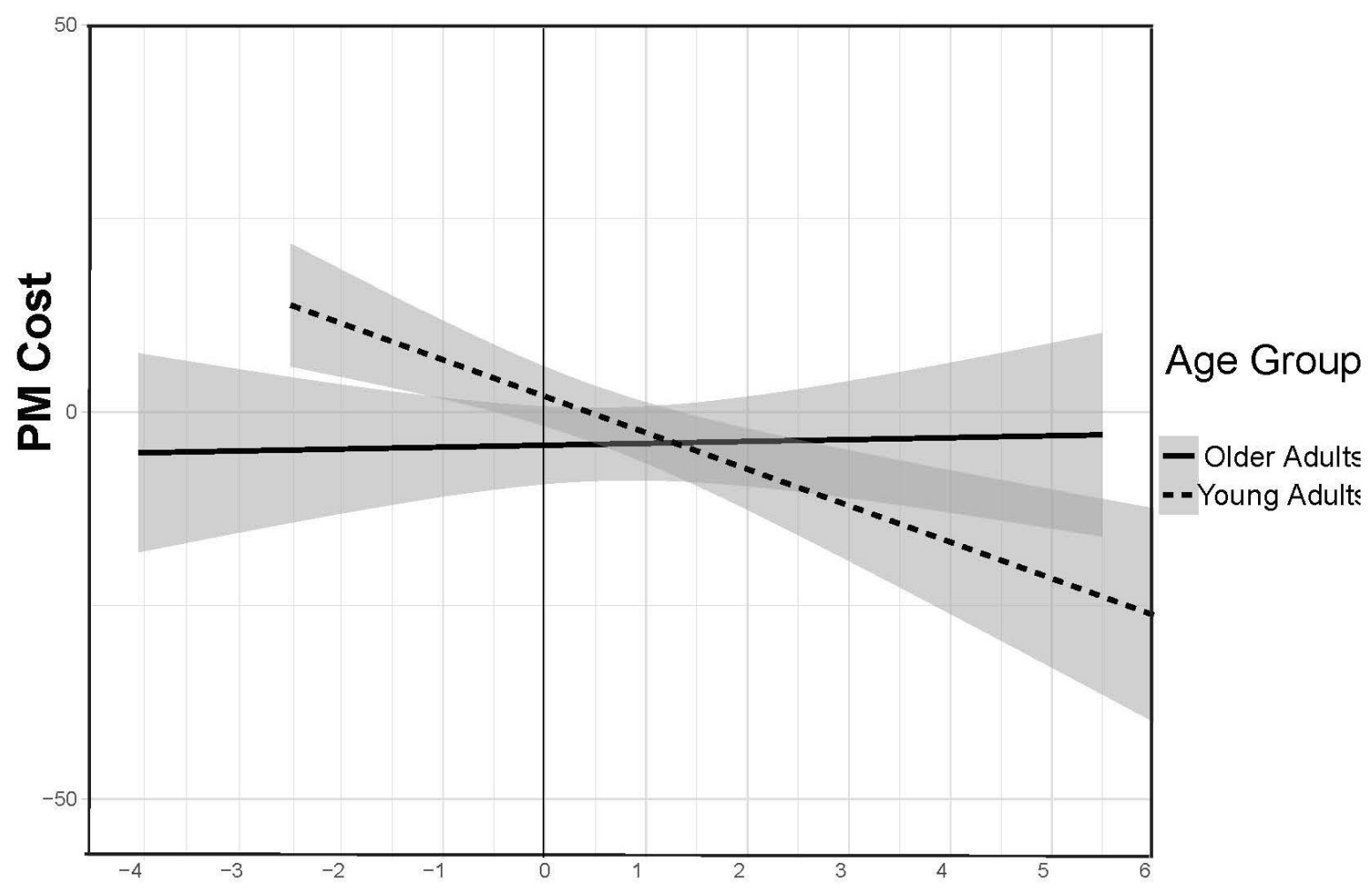

Changes in Valence

Figure 4. PM cost as a function of changes in valence for young and older adults. The shaded areas represent $95 \%$ confidence intervals. 